\title{
Slovenia, Country Risk, and FDI - Three Levels of Analysis Mixed Methodologies Offer Fresh Insights
}

\author{
Edward M. Jankovic, D.I.B.A. \\ Department of Finance \\ Trefz School of Business \\ University of Bridgeport
}

\section{Abstract}

Slovenia is the first of the recent Accession countries to the EU to adopt the Euro as its currency. Its location at the top of the Balkan line and just under Austria and Italy makes it psychologically advantageous as a bridge for commercial and financial entry to other Balkan nations. Advances in Slovenia's steps to integration with the EU and other international organizations can be a model for further EU expansion and other current Accession countries in the process of adopting EU policies.

The purpose of this study is to discover relationships among FDI (Foreign Direct Investment), country risk, investor expectations, and certain financial variables in Slovenia, and to do this on three levels of analysis: standard statistical analysis, chart or graphical analysis, and a qualitative field study. The quantitative work displays relationships of the variables using cointegration and VAR analyses. The chart section imposes visually the variable of country risk on the same data source as the statistical analysis. And the field study incorporates aspects of international finance such as legal, historic, social, and political issues into the research.

Therefore, the results of this research can be more accessible to those who know qualitative methodology but do not know international finance, and to those who know international finance but are not familiar with qualitative research, opening both fields to wider audiences.

Conclusions reached are that FDI is necessary for Slovenia's continued economic growth and continued freedom. By illustrating the connections of the variables to FDI, policymakers have a guide to the benefits of market-oriented principles in all areas of the economy, social programs, politics, and financial markets. The results of the research will help Slovenia improve liquidity and transparency of markets, decrease corruption, improve laws, and gain investment needed to pay for the activities and programs of EU membership.

JEL classification: F15, F30, G15, O50, O57, B00

Keywords: Slovenia, FDI, qualitative methodology, transition economics

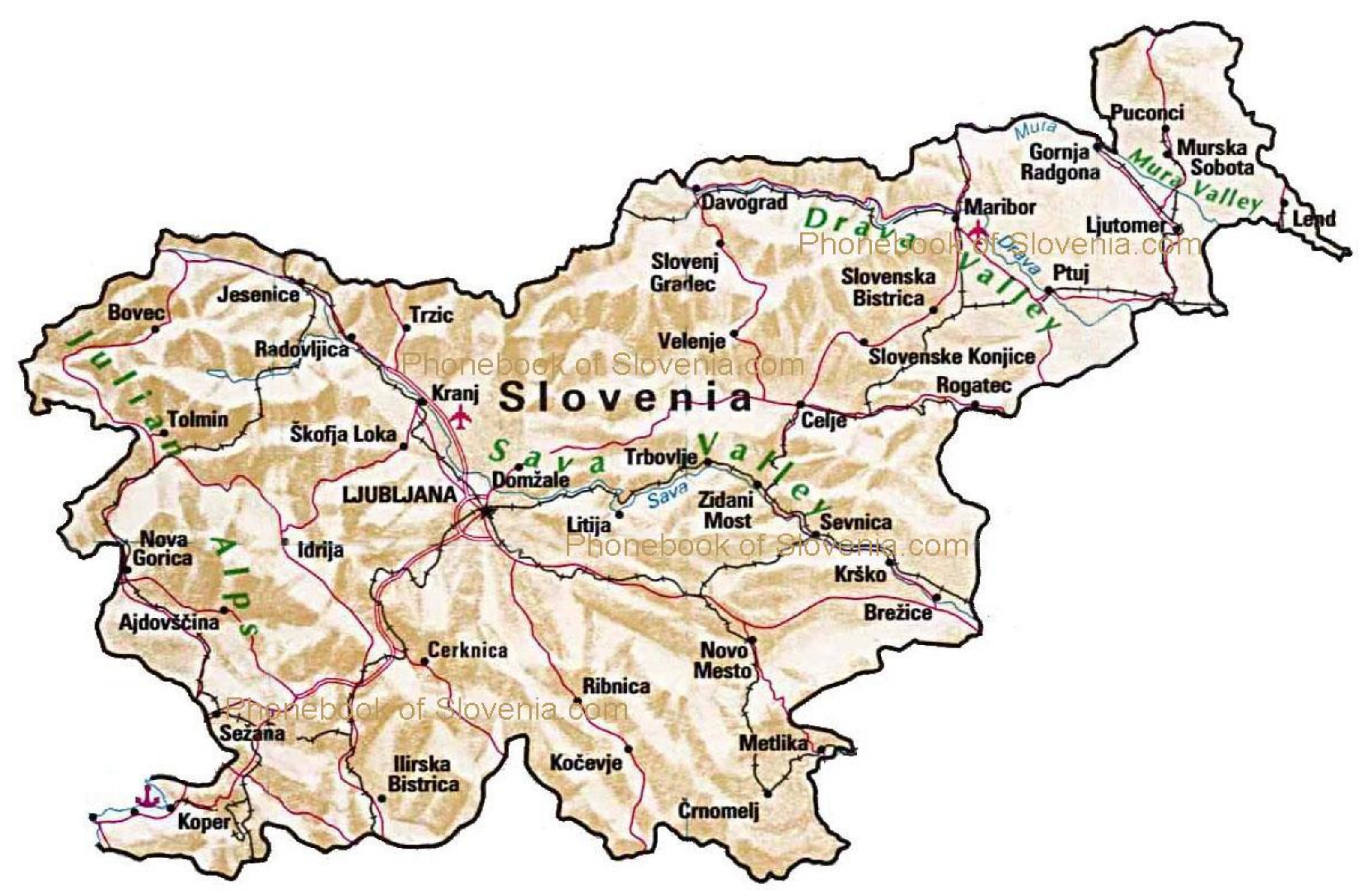

